\title{
Research on differential game model of vertical cooperation of dual-channel low-carbon supply chain
}

\author{
Mei-xiang Wu, Cheng-dong Shi, Qiang Sun
}

School of management, Shan Dong University of technology, China

\begin{abstract}
Direct channels for manufacturers have become the norm. For the study of double sales channels, single manufacturer, reducing emissions and single retailer promotion coordination problems, to emissions reductions as state variables, assume that the market demand by reduction, as well as the influence and promotion efforts to build a single manufacturer and single retailer of three kinds of differential game model, to investigate the condition of double channels involved in cooperation and the influence of various parameters on the members of the decision. It is found that under certain conditions, cost-sharing contracts can improve the profits of each member and the system. With the increase of the ratio of manufacturer to retailer's promotion cost, the improvement effect of the contract on the profit of the two members changed significantly. High retailers' low carbon advertising cost and discount rate factor will reduce the improvement effect of cost-sharing contract.
\end{abstract}

Keywords-Differential game; Low-carbon supply chain ;Dual channel ;Emission reduction promotion cooperation.

\section{INTRODUCTION}

The greenhouse effect is the main reason for the frequent occurrence of global climate change and extreme weather, and the carbon emission from human economic activities is the main source of the greenhouse effect ${ }^{[1]}$. At the Copenhagen conference, the Chinese government made a clear commitment: by 2020, China's carbon dioxide emissions per unit of GDP will be reduced by $40-50 \%$ compared with $2005^{[2]}$. At present, the government has formulated a series of low-carbon policies such as tax, subsidy and carbon trading, manufacturers have carried out many emission reduction actions, such as ecological research and development, energy conservation etc, and retailers have launched low-carbon price discount, low-carbon label, low-carbon consumption rebate and other guiding activities, which have accelerated the implementation of the low-carbon concept ${ }^{[3]}$. However,
Galanz press spokesman Ji-lie Lu, pointed out in an online interview with China economic net that the real driving force behind the low-carbon concept of the 12th five-year plan is consumers. Namely the implementation of low-carbon concept, low-carbon products consumption scale is the key. How to achieve the concept of low-carbon environmental protection popular? The key is to segment consumer demand market and study how manufacturers and retailers cooperate under the guidance of government policies.

With the development of the Internet and the popularity of e-commerce, manufacturers have opened direct channels. Considering that the product emission reduction is affected by the manufacturer's emission reduction efforts, the multi-cycle continuous production has dynamic changes, and the business operation is often cross-cycle rather than single-cycle. Therefore, from a 
long-term and dynamic perspective, it is of great significance to study the low-carbon promotion cooperation between the upstream and downstream of the supply chain in the context of dual-channel sales.

\section{LITERATURE REVIEW}

In terms of dual-channel pricing, most scholars focus on the channel structure of supply chain and analyze the conditions for opening direct selling channels and supply chain coordination contracts. Chianget al. ${ }^{[6]}$ believe that the opening of direct sales channels can increase their own demand and profits, making retailers lower prices. Dumrongsiri et al. ${ }^{[7]}$ believe that increasing direct sales channels can improve the overall benefits of dual channels, while improving the service quality of retailers can increase the common interests of channel members. Chen et $\mathrm{al}^{[8]}$. proposed a dual-channel supply chain that could be coordinated by two-part pricing or revenue-sharing contracts. Shi-hui Yang [9] studied the two-channel low-carbon supply chain game led by manufacturers, solved the optimal solution under different channel structures, and proposed that the cost-sharing contract + revenue-sharing contract could realize supply chain coordination.

In terms of low-carbon supply chain cooperation, carbon emissions are mostly taken as the state variable to analyze the coordination between upstream and downstream.Wei-dong Huang ${ }^{[10]}$ studied the collaborative technological innovation of low-carbon supply chain by using the game theory of differential game, and compared the collaborative technological innovation decisions of enterprises under different cooperation modes. From the perspective of goodwill decline,Qin-peng Wang [11] compared three cooperative strategies led by R, namely, manufacturers, energy conservation and emission reduction, and retailers, low-carbon promotion supply chain. Dao-zhi Zhao ${ }^{[12]}$ took carbon emission decline as the state variable and studied the problem of joint emission reduction and low-carbon publicity cooperation in upstream and downstream of $\mathrm{R}$ competitive low-carbon supply chain from a dynamic perspective.

In terms of upstream and downstream advertising cooperation in the supply chain, most scholars take the brand image as the state variable to explore the influence of the evolution of brand image on the interests of members of the supply chain. JØrgensenetc ${ }^{[13-18]}$ from the perspective of long-term ads and short-term, through the brand image construction of state variables, manufacturers use the advertising to build goodwill and retailer promotion of dynamic game, degree students Fu Qiang ${ }^{[19]}$ consider the retailer promotion has a negative effect on manufacturer brand reputation, build a game model of single manufacturer + retailers, contrast different cooperative game case members advertising decisions; $\mathrm{He}^{[20]}$ constructed a differential game model of single manufacturer + double retailers, and compared the problem of medium advertising cooperation between upstream and downstream enterprises under two conditions: manufacturer sharing and non-sharing of advertising costs. Zhi-yongZhang ${ }^{[21]}$ studied the advertising cooperation and coordination strategy between manufacturers and retailers under dual channels from a dynamic perspective. Da-mingYou ${ }^{[22]}$ compared supply chain feedback balancing strategies under different decisions by taking low-carbon products and goodwill as state variables in terms of ecological r\&d, promotion and pricing of low-carbon supply chains.

Most of the above studies unilaterally studied dual-channel structure, upstream and downstream differential game of supply chain, advertising cooperation and low-carbon supply chain coordination, but few research achievements were made on low-carbon dual-channel supply chain and upstream and downstream collaborative emission reduction cooperation. Based on this, based on the research of Chun-qiu $\mathrm{Xu}^{[23]}$, this paper expands online direct selling and traditional sales channels, discusses the dynamic cooperation between the upstream and downstream enterprises of low-carbon supply chain, and analyzes the establishment conditions of cost-sharing contracts and the optimization effect of contracts on members' profits, so as to assist enterprises to select and formulate contracts according to the actual situation.

\section{PROBLEM DESCRIPTION AND BASIC} ASSUMPTIONS 


\subsection{Problem description}

In order to realize the innovation of emission reduction and low-carbon promotion of dual-channel sales supply chain, this paper takes the secondary supply chain led by manufacturers as the research object, that is, manufacturers call on retailers to build a low-carbon cooperation center, manufacturers are responsible for promoting ecological research and development, low-carbon certification, energy-saving manufacturing, and build an online direct selling platform for online sales. Retailers are responsible for designing and implementing promotion plans for low-carbon products, such as price discounts, low-carbon labels, and rebates for low-carbon consumption. To encourage retailers to participate in collaborative innovation of emissions-reduction technologies, manufacturers will share a percentage of the retailers' $r \& d$ costs. This paper focuses on discussing the effect of contract formation conditions and contract parameters on the coordination optimization effect.

\subsection{Definition of parameters}

$J_{i}^{j}, Q_{i}^{j}, V_{i}^{j}, E_{i}^{j}, \mathrm{i}=\mathrm{m}, \mathrm{r}, \mathrm{sc} ; \mathrm{j}=C, N, F$ is the optimal profit, the optimal order quantity, the optimal value and the members' efforts under different decision-making environments, where $\mathrm{m}, \mathrm{r}$, sc refers to the manufacturer, the retailer and the supply chain respectively, and $C, N, F$ refers to the three decision-making situations of centralized decision-making, no-cost-sharing master-slave game and cost-sharing master-slave game respectively. $I_{m}$ is manufacturer's investment in emission reduction; $I_{r}$ is low carbon promotion cost for retailers; $E_{m}(\mathrm{t})$ is manufacturer's efforts to reduce emissions; $E_{r}(\mathrm{t})$ is retailers' low-carbon promotion efforts; $\eta_{m}, \eta_{r}>0$ is the cost coefficient of manufacturer's emission reduction efforts and the cost coefficient of retailer's low-carbon promotion; $X(t)$ is system emission reduction state variable; $\gamma, \theta$ is influence coefficient of manufacturer's emission reduction efforts on emission reduction performance and emission reduction self-attenuation factor; $S(\mathrm{t})$ is manufacturer's subsidy coefficient for low-carbon promotion of retailers; $\alpha$ is the number of basic consumers, $\delta, 1-\delta$ is the proportion of direct selling and physical stores; $\beta_{r}, \beta_{d}>0$ is the influence factors of system emission reduction performance on dual-channel demand; $\rho>0$ is discount rate; $\lambda, k>0$ refers to the unit product revenue of the manufacturer's traditional channel and the retailer's retail channel respectively, and is constant; $\mu$ is impact factors on demand for retailer promotional effort level.

\section{3 model assumptions}

- In order to reduce emissions, manufacturers need to upgrade production technology, machinery and equipment, apply for low-carbon certification, etc. The investment of manufacturers $I_{m}$ is related to their efforts $E_{m}(\mathrm{t})$, assuming that $I_{m}=0.5 \eta_{m} E_{m}^{2}$. The cost of promoting low-carbon advertising for retailers $I_{r}$ is related to their efforts $E_{r}(\mathrm{t})$ assuming that $I_{r}=0.5 \eta_{r} E_{r}^{2}$.

- Manufacturer's emission reduction efforts affect carbon emission reduction, and the emission reduction dynamic changes. System emission reduction performance is $\quad X(\mathrm{t})=\gamma E_{m}(t)-\theta X(\mathrm{t})$

- In order to stimulate retailers' low-carbon publicity, the manufacturer shall give partial compensation to the retailers' low-carbon publicity investment, and the compensation ratio is $S(\mathrm{t})$, and $0<S(\mathrm{t})<1$.

- The market demand is composed of direct selling and retail, assumed that $Q_{d}(t)=\delta \alpha+\beta_{d} X(t)$, $Q_{r}(t)=(1-\delta) \alpha+\beta_{r} X(t)+\mu E_{r}(t) \quad$.Because the promotion publicity in the promotion process of retailers will increase consumers' awareness of low-carbon consumption, $\beta_{r}>\beta_{d}$.

- Assume the manufacturer's profit margin per unit product in direct selling and traditional channels, retailer's profit margin per unit product is $\lambda>0$, and $k>1$.

- Suppose that $\rho>0$, risk neutral, both members make rational decisions, and the goal is to maximize their own profits.

\section{ANALYSIS ON THE COOPERATION MODEL OF EMISSION REDUCTION AND PROMOTION OF DUAL-CHANNEL LOW-CARBON SUPPLY CHAIN}

\subsection{Centralized decision model $(C)$}

In actual operation, it is difficult to have a central decision maker whose goal is to maximize the overall benefit of the supply chain, but the centralized decision model is the ultimate goal of contract design. Centralized decision making:

$$
\max _{E_{m}(t), E_{r}(t)} J_{s c}^{C}=\int_{0}^{\infty} e^{-\rho t}\left\{\mathrm{Q}_{d}^{C}+k \mathrm{Q}_{r}^{C}+\lambda \mathrm{Q}_{r}^{C}-\mathrm{I}_{m}\left(\mathrm{E}_{m}(\mathrm{t})\right)-\mathrm{I}_{r}\left(\mathrm{E}_{r}(\mathrm{t})\right)\right\} \mathrm{dt}
$$

Refer to the solution of the optimal control problem ${ }^{[13]}$, and assume that the parameters in the model are constants independent of time. In addition, for the convenience of writing, the time will not be listed below. The solution result is shown in proposition 1 
Proposition 1:Equilibrium result of differential game under centralized decision:

$$
E_{m}^{C}=\frac{V_{s c}^{C^{\prime}}(\mathrm{X}) \gamma}{\eta_{m}}=\frac{\left[\beta_{d}+\beta_{r}(k+\lambda)\right] \gamma}{(\rho+\theta) \eta_{m}}, E_{r}^{C}=\frac{(k+\lambda) \mu}{\eta_{r}}
$$

Optimal trajectory of system emission reduction performance:

$$
X(\mathrm{t})^{C}=\left\{X_{0}-\frac{\left[\beta_{d}+\beta_{r}(k+\lambda)\right] \gamma^{2}}{(\rho+\theta) \theta \eta_{m}}\right\} \mathrm{e}^{-\theta t}+\frac{\left[\beta_{d}+\beta_{r}(k+\lambda)\right] \gamma^{2}}{(\rho+\theta) \theta \eta_{m}}
$$

System profit optimal value function: $J_{s c}^{C}(\mathrm{X}, \mathrm{t})=e^{-\rho t}\left(\mathrm{a}_{1}^{C} \mathrm{X}+b_{1}^{C}\right) \quad$, In which:

$a_{1}^{C}=\frac{\beta_{d}+\beta_{r}(k+\lambda)}{\rho+\theta}, b_{1}^{C}=\frac{\delta \alpha+(k+\lambda)(1-\delta) \alpha}{\rho}+\frac{(k+\lambda)^{2} \mu^{2}}{2 \rho \eta_{r}}+\frac{\left[\beta_{d}+\beta_{r}(k+\lambda)\right]^{2} \gamma^{2}}{2 \rho \eta_{m}(\rho+\theta)^{2}}$ (6)

\subsection{Stackelberg game model without cost sharing(N)}

The manufacturer is the leading party, and the game order is as follows: firstly, the manufacturer determines $\mathrm{E}_{m}$; then, the retailer determines $E_{r}$ Both parties make decisions:

$$
\max _{E_{m}} J_{m}^{N}=\int_{0}^{\infty} e^{-\rho t}\left\{\mathrm{Q}_{d}^{N}+\lambda \mathrm{Q}_{r}^{N}-\mathrm{I}_{m}\left(\mathrm{E}_{m}\right)\right\} \mathrm{dt}
$$

$$
\max _{E_{r}} J_{r}^{N}=\int_{0}^{\infty} e^{-\rho t}\left\{k \mathrm{Q}_{r}^{N}-\mathrm{I}_{r}\left(\mathrm{E}_{r}\right)\right\} \mathrm{dt}
$$

Proposition 2:

equilibrium result of differential game without cost sharing: $E_{m}^{N}=\frac{\left(\beta_{d}+k \beta_{r}\right) \gamma}{(\rho+\theta) \eta_{m}}, E_{r}^{N}=\frac{\lambda \mu}{\eta_{r}}$

Optimal trajectory of system emission reduction performance:

$$
X(\mathrm{t})^{N}=\left\{X_{0}-\frac{\left(\beta_{d}+k \beta_{r}\right) \gamma^{2}}{\theta(\rho+\theta) \eta_{m}}\right\} \mathrm{e}^{-\theta t}+\frac{\left(\beta_{d}+k \beta_{r}\right) \gamma_{1}^{2}}{\theta(\rho+\theta) \eta_{m}}
$$

System profit optimal value function:

$$
J_{m}^{N}(\mathrm{X}, \mathrm{t})=e^{-\rho t}\left(\mathrm{a}_{3}^{N} \mathrm{X}+b_{3}^{N}\right), J_{r}^{N}(\mathrm{X}, \mathrm{t})=e^{-\rho t}\left(\mathrm{a}_{4}^{N} \mathrm{X}+b_{4}^{N}\right),
$$$$
a_{3}^{N}=\frac{\beta_{d}+k \beta_{r}}{\rho+\theta}, b_{3}^{N}=\frac{\delta \alpha+k(1-\delta) \alpha}{\rho}+\frac{\lambda k \mu^{2}}{\rho \eta_{r}}+\frac{\left(\beta_{d}+k \beta_{r}\right)^{2} \gamma^{2}}{2 \rho \eta_{m}(\rho+\theta)^{2}}, a_{4}^{N}=\frac{\lambda \beta_{r}}{\rho+\theta}, b_{4}^{N} \stackrel{d \lambda\left(\mathbb{E}_{r}^{F}-\delta\right) \alpha}{d S \rho} \oplus \frac{\lambda^{2} \mu^{2}}{2 \rho \eta_{r}}+\frac{\left(\beta_{d}+k \beta_{r}\right) \lambda \beta_{r} \gamma^{2}}{\eta_{m} \rho(\rho+\theta)^{2}}
$$

\subsection{Stackelberg game model with cost sharing(F)}

Manufacturers play a leading role in the cooperation between emission reduction and low-carbon promotion. In order to encourage retailers to promote low-carbon promotion, manufacturers give retailers a certain proportion of subsidies. From a long-term and dynamic perspective, the game between the two is Stackelberg differential game, which is represented by $\mathrm{F}$. The game process is as follows: first, the manufacturer decides the degree of emission reduction efforts $E_{m}^{F}$ and the proportion of retailers' low-carbon promotion costs $\mathrm{S}$; Retailers then decide how hard to promote low-carbon products $E_{r}^{F}$. The decision of both parties is:

$$
\begin{aligned}
& \max _{E_{m}, \mathrm{~S}} J_{m}^{F}=\int_{0}^{\infty} e^{-\rho t}\left\{\mathrm{Q}_{d}^{F}+k \mathrm{Q}_{r}^{F}-\mathrm{I}_{m}\left(\mathrm{E}_{m}\right)-S \mathrm{I}_{r}\left(\mathrm{E}_{r}\right)\right\} \mathrm{dt} \\
& \max _{E_{r}} J_{r}^{F}=\int_{0}^{\infty} e^{-\rho t}\left\{\lambda \mathrm{Q}_{r}^{F}-(1-S) \mathrm{I}_{r}\left(\mathrm{E}_{r}\right)\right\} \mathrm{dt}
\end{aligned}
$$

Proposition 3:

Equilibrium result of differential game under cost sharing: $E_{m}^{F}=\frac{\left(\beta_{d}+\lambda \beta_{r}\right) \gamma}{(\rho+\theta) \eta_{m}}, E_{r}^{F}=\frac{\lambda \mu}{(1-S) \eta_{r}}$

Optimal track of system emission reduction performance:

$$
X(t)^{F}=\left\{\mathrm{X}_{0}-\frac{\left(\beta_{d}+\lambda \beta_{r}\right) \gamma^{2}}{\theta(\rho+\theta) \eta_{m}}\right\} \mathrm{e}^{-\theta t}+\frac{\left(\beta_{d}+\lambda \beta_{r}\right) \gamma^{2}}{\theta(\rho+\theta) \eta_{m}}
$$

The optimal value function of system profit is:

$$
\begin{aligned}
& J_{m}^{F}(\mathrm{X}, \mathrm{t})=e^{-\rho t}\left(\mathrm{a}_{5}^{F} \mathrm{X}+b_{5}^{F}\right), J_{r}^{N}(\mathrm{X}, \mathrm{t})=e^{-\rho t}\left(\mathrm{a}_{6}^{F} \mathrm{X}+b_{6}^{F}\right), \\
& a_{5}^{F}=\frac{\beta_{d}+k \beta_{r}}{\rho+\theta}, b_{5}^{F}=\frac{\delta \alpha+(1-\delta) \mathrm{k} \alpha}{\rho}+\frac{k \lambda \mu^{2}}{\rho(1-S) \eta_{r}}-\frac{S \lambda^{2} \mu^{2}}{2 \rho(1-S)^{2} \eta_{r}}+\frac{\left(\beta_{d}+k \beta_{r}\right)^{2} \gamma^{2}}{2 \eta_{m} \rho(\rho+\theta)^{2}} \\
& a_{6}^{F}=\frac{\lambda \beta_{r}}{\rho+\theta}, b_{6}^{F}=\frac{\lambda(1-\delta) \alpha}{\rho}+\frac{\lambda^{2} \mu^{2}}{2 \rho(1-\mathrm{S}) \eta_{r}}+\frac{\lambda \beta_{r}\left(\beta_{d}+k \beta_{r}\right) \gamma^{2}}{\rho \eta_{m}(\rho+\theta)^{2}}
\end{aligned}
$$

Because $S=\frac{2-\lambda}{1+\lambda}>0,1-S=\frac{2 \lambda-1}{1+\lambda}, 0.5<\lambda<2$

Explanation: formula (17) $0.5<\lambda<2$ is the establishment condition of $\mathrm{S}$, that is, the establishment condition of $\mathrm{S}$ is that the retailer's marginal revenue of traditional channel should not be less than half of the manufacturer's marginal revenue of direct selling channel, and should not be more than 2 times of the marginal

\subsection{Comparison of the three models}

Proof: $\quad E_{m}^{C}-E_{m}^{F}=\frac{\lambda \beta_{r} \gamma}{(\rho+\theta) \eta_{m}}>0, E_{m}^{F}-E_{m}^{N}=0$

$E_{r}^{C}-E_{r}^{N}=\frac{k \mu}{\eta_{r}}>0, E_{r}^{F}-E_{r}^{N}=\frac{S \lambda \mu}{(1-S) \eta_{r}}>0, \frac{d \square E_{r}^{F-N}}{d S}=\frac{\lambda \mu}{(1-S) \eta_{r}}+\frac{S \lambda \mu}{(1-S)^{2} \eta_{r}}>0$

Description: 
- under centralized decision-making, manufacturers and retailers have the highest emission reduction efforts.

- After the introduction of cost-sharing contract, the level of retailers' promotional efforts increased, and the rate of improvement of retailers' promotional efforts was positively correlated with manufacturers' cost-sharing ratio.

4.4.2 Comparison of member benefits and member incentive effect before and after the introduction of cost contract

$$
\begin{aligned}
& V_{m}^{F}(\mathrm{X})-V_{m}^{N}(\mathrm{X})=\frac{S \lambda \mu^{2}(2 \mathrm{k}-\lambda-2 k \mathrm{~S})}{2 \rho(1-S)^{2} \eta_{r}}, \\
& V_{r}^{F}(\mathrm{X})-V_{r}^{N}(\mathrm{X})=\frac{S \lambda^{2} \mu^{2}}{2 \rho(1-\mathrm{S}) \eta_{r}}>0, \\
& \square V_{m}^{F-N}(\mathrm{X})-\square V_{r}^{F-N}(\mathrm{X})=\frac{S \lambda \mu^{2}}{2 \rho(1-\mathrm{S})^{2} \eta_{r}}[2 \mathrm{k}-2 \lambda-(2 \mathrm{k}-\lambda) \mathrm{S}] \\
& V_{s c}^{C}(\mathrm{X})-V_{s c}^{F}(\mathrm{X})=\frac{\mu^{2}}{2 \rho \eta_{r}} \frac{\left(k^{2}-k^{2} S+\lambda^{2}\right)}{(1-\mathrm{S})^{2}}+\frac{\lambda^{2} \beta_{r}^{2}}{2 \rho \eta_{m}(\rho+\theta)^{2}}>0
\end{aligned}
$$

Description:

- Regardless of the cost-sharing factor, the contract can increase the retailer's profits. When $S<(2 k-\lambda) / 2 k$, the manufacturer's profit was higher than its profit without cost sharing, which was the manufacturer's participation constraint and also the condition of establishing the cost sharing contract.

- When $(2 k-2 \lambda) /(2 k-\lambda)<S<(2 k-\lambda) / 2 k$, the improvement effect of the contract on the retailer is greater than that of the manufacturer; When
$(2 k-2 \lambda) /(2 k-\lambda)<S<(2 k-\lambda) / 2 k$, the improvement effect on the manufacturer is greater than that on the retailer. At this point, the manufacturer should use the cost-sharing contract to encourage the retailer to promote low-carbon.

- Cost sharing contract effect on the improvement of the each member's profits are Influenced by the low carbon publicity cost coefficient of retailers $\eta_{r}$, the proportion of manufacturers to bear the retailer's low carbon advertising costs $\eta_{m}$, the manufacturers and retailers channel marginal revenue $k, \lambda$,the demand impact factor $\mu$ and discount rate $\rho$ of retailers' promotion effort level. The influence relationship of some parameters will be analyzed in the example

- The optimal profit of supply chain system under centralized decision is better than that without cost sharing and contract coordination. The retailer takes the initiative to participate in the contract, and the manufacturer takes part in the contract on the condition that the profit after the cooperation is better than the profit without cost sharing. As for the distribution of system incremental profit, it depends on the negotiation ability of both sides.

\section{ANALYSIS OF EXAMPLES}

The above theoretical analysis draws general conclusions. In order to more specifically demonstrate the impact of cost-sharing contracts on members, specific examples are given below. Assumptions:

$\eta_{m}=5, \eta_{r}=4, \rho=0.9, \gamma=2, \theta=1, \beta_{r}=3, \beta_{d}=2, \mu=2, \delta=0.4, \alpha=5, k=2, \lambda=1.5, X_{0}=0$

\subsection{Comparison of improvement effect of cost-sharing coefficient}

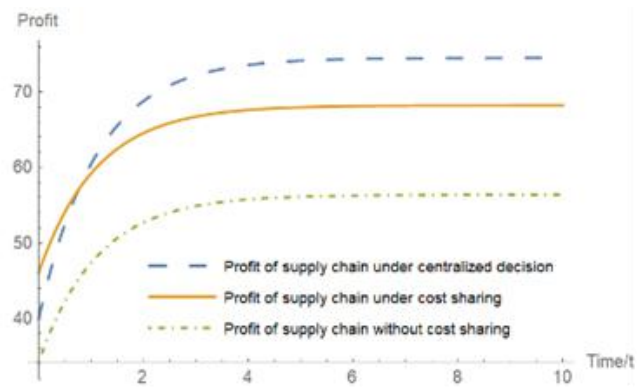

Fig.1 System profit comparison of Cost-sharing and centralized decision-making

- Figure 1 shows that the system profit is the largest under centralized decision-making, followed by the cost-sharing system, and the system profit without cost-sharing is the smallest

- $\quad$ Figure 2 shows that the profit of retailers under cost sharing is higher than that without cost sharing, and

\section{on member and system profit}

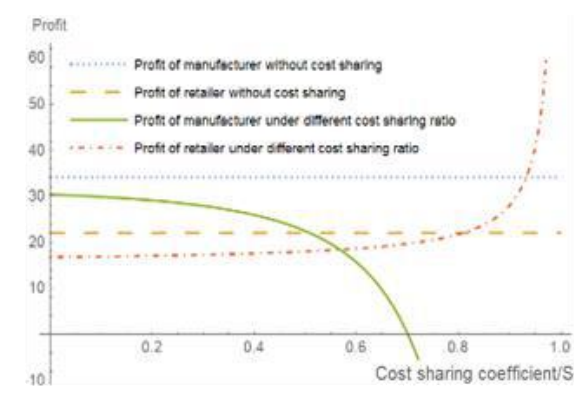

Fig.2 The influence of S to profit of Supply chain member

the profit improvement effect increases with the increase of cost sharing ratio. When $S<(2 k-\lambda) / 2 k=0.73$, manufacturers' profit under cost sharing is higher than that without cost sharing. When $S>0.73$, manufacturers' profit drops sharply and is lower than that without cost sharing. 


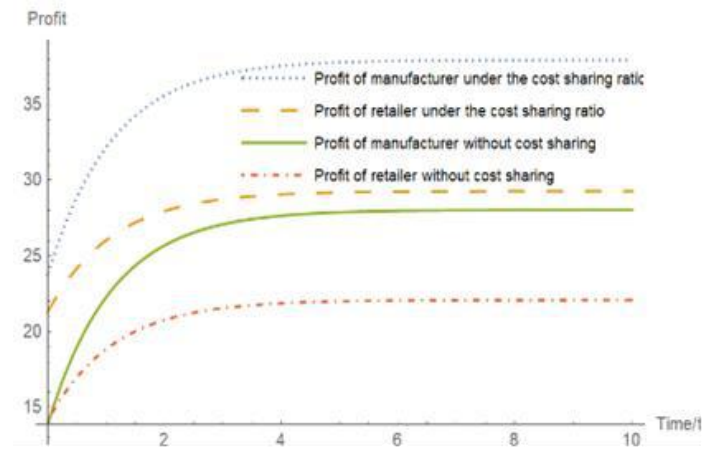

Fig. 3 Cost-sharing comparison of Supply chain member $(S=0.3)$

Figure 3,4 shows that cost-sharing improved profits for both manufacturers and retailers. However, different cost-sharing ratios have different effects on the improvement of members' profits, which can be proved by the vertical distance between the two members' profits before and after the cost-sharing. As shown in figure 3, $S=0.3$ is taken to verify that when $(2 k-2 \lambda) /(2 k-\lambda)=0.4<S<0.73=(2 k-\lambda) / 2 k \quad$ is used, the

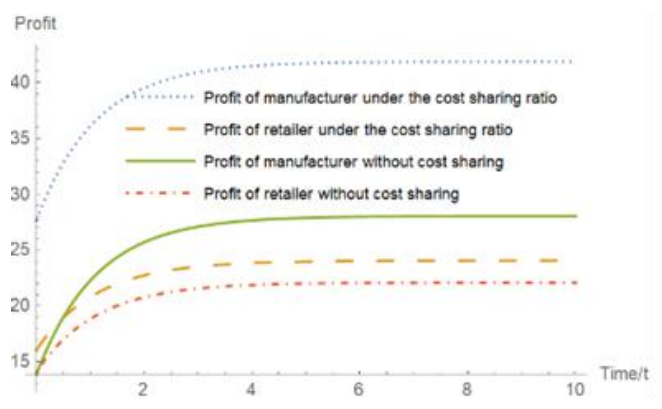

Fig.4 Cost-sharing comparison of Supply chain member $(S=0.6)$

cost-sharing contract has a better effect on the improvement of manufacturer's profit than on the improvement of retailer's profit. Fig4 shows that $S=0.6$ is taken to verify that when $(2 k-2 \lambda) /(2 k-\lambda)=0.4<S<0.73=(2 k-\lambda) / 2 k \quad, \quad$ cost-sharing contracts improve retailers' profits better than manufacturers'.

\subsection{The effect of parameters $\eta_{r}, \beta, \mu$ on the improvement effect of cost-sharing contracts}

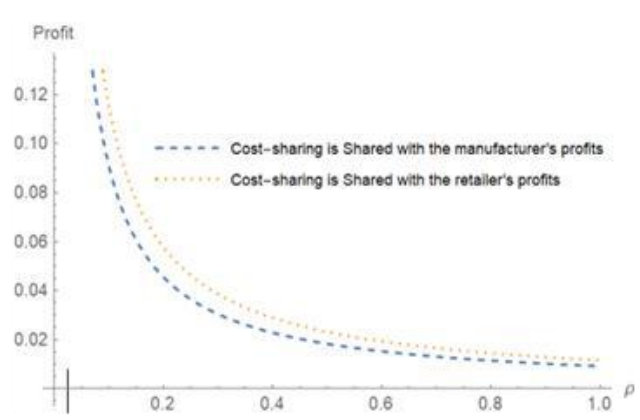

Fig.5 The influence of $\rho$ to improve the effect of cost sharing contract

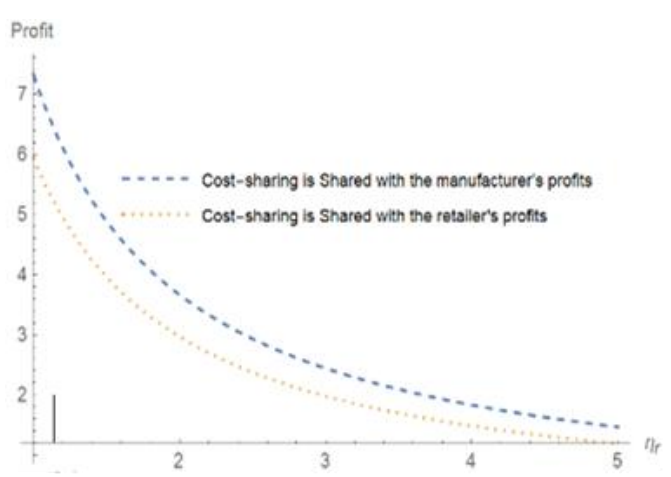

Fig.7 The influence of $\eta_{r}$ to improve the effect of cost sharing contract

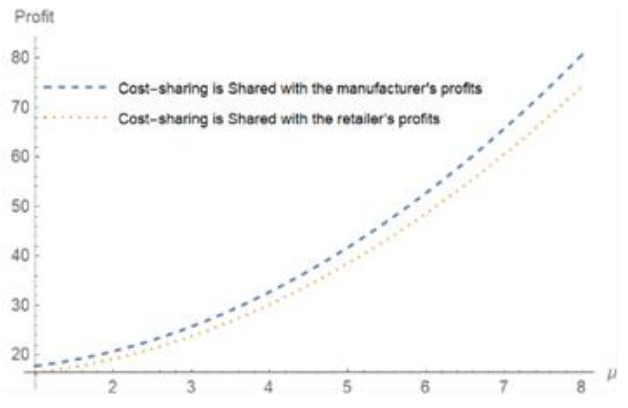

Fig. 6 The influence of $\mu$ to improve the effect of cost sharing contract

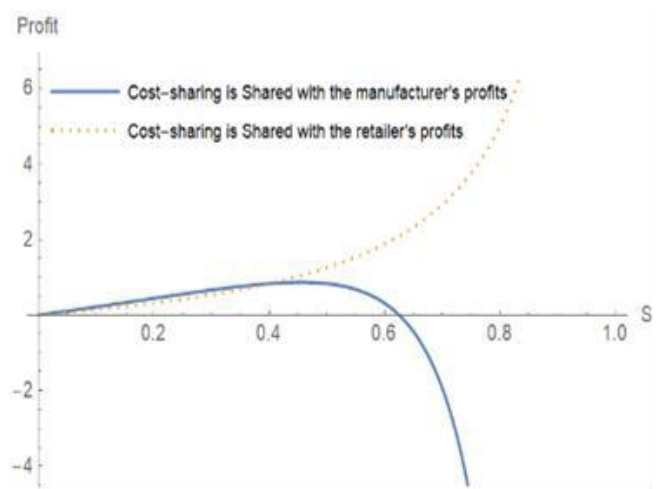

Fig.8 The influence of $S$ to improve the effect of cost sharing contract

- In figure 5-7 $S=0.3$, the three figures are verified

ISSN: 2456-7620 
again: when $S<(2 k-2 \lambda) /(2 k-\lambda)=0.4$, the contract has a better effect on the manufacturer's profit improvement;

- Figure 5 shows that the improvement effect of cost-sharing contracts on members' profits is negatively correlated with the discount rate $\rho$. However, the effect on the profit improvement effect of the two members is synchronous, so the parameters $\rho$ are not sensitive to the signing of the contract between the two parties.

- Figure 6 shows that with the increase of consumers' sensitivity to retailers' low-carbon promotion $\mu$, the cost-sharing contract has a more obvious effect on the improvement of members' profits. The more sensitive consumers are to low-carbon promotion, the greater the difference in profit improvement between the two members, and the greater the incentive for manufacturers to increase subsidies to retailers.

- Figure 7 shows that the improvement effect of cost-sharing contract on members' profits decreases with the increase of retailers' low-carbon publicity cost coefficient $\eta_{r}$. The higher the cost coefficient of retailers' low-carbon publicity efforts, the less obvious the incentive effect of manufacturers. Therefore, manufacturers need to take the issue of low-carbon publicity costs into comprehensive consideration when making decisions.

- Figure 8 shows that: when $S<(2 k-2 \lambda) /(2 k-\lambda)=0.4$, the contract has a better effect on the improvement of manufacturer's profit, but a smaller effect on both sides.

When $(2 k-2 \lambda) /(2 k-\lambda)=0.4<S<0.73=S<(2 k-\lambda) / 2 k$, the contract improves the retailer's profit better; When $S<(2 k-2 \lambda) / 2 k=0.73$, manufacturers withdraw from the low-carbon publicity cooperation. Therefore, when retailers make decisions, they need to take into account the leading role of manufacturers and the demarcation point of cost-sharing ratio.

\section{CONCLUSION}

From the perspective of long-term dynamic joint emission reduction and low-carbon publicity between manufacturers and retailers, this paper constructs three differential game models under the dual-channel sales platform. The following conclusions can be obtained through the solution of the model:

- Retailers' active participation in emission reduction promotion cooperation, $S<(2 k-\lambda) / 2 k$ is a prerequisite for manufacturers to sign cost-sharing contracts.

- When the cost-sharing ratio is small and in a range $S \in(0,(2 k-2 \lambda) /(2 k-\lambda)]$, the effect of the contract on the improvement of the manufacturer's profit is better than that of the retailer's profit, and the manufacturer has the incentive to increase the cost subsidy ratio. When the cost-sharing ratio is further increased to the range $S \in[(2 k-2 \lambda) /(2 k-\lambda),(2 k-\lambda) / 2 k]$, the cost-sharing contract improves the retailer's profit better than the manufacturer's profit, but the manufacturer's profit is still higher than the profit without cost-sharing, so the manufacturer still signs the contract voluntarily. When $S \in[(2 k-\lambda) / 2 k, 1]$, the manufacturer's profit was lower than the profit without cost sharing, so the manufacturer withdrew from the low-carbon publicity cooperation.

- The improvement effect of cost-sharing contract on members' profits is positively correlated with the impact factor of retailers' promotion efforts on demand $\mu$, negatively correlated with the low carbon publicity cost coefficient $\eta_{r}$ and discount rate $\rho$, and

$\eta_{r}, \mu$ are the sensitive parameter signed by both parties.

It emphasized under double sales channels, low carbon cost sharing agreement between supply chain members to improve members of the supply chain profit, the influence of model does not consider the government subsidies, such as carbon trading policy, bidirectional free-riding environmental regulations affect members reduction decision, and the state of this contract fails to reach the centralized decision-making, the further research direction.

\section{REFERENCES}

[1] DINAN T. Policy options for reducing $\mathrm{CO} 2$ emissions[R].Washington D.C.,The congress of the United States, Congressional Budget Office, 2008. http://www.cbo.gov/ftpdocs/89xx/doc8934/02-12-Carbon.p df.

[2] State council: carbon dioxide emissions per unit of GDP will be reduced by $40-50 \%$ by 2020 compared with 2005 ,

[EB/OL].(2014-09-09).

http://www.chinanews.com/gn/2014/09-19/6609315.shtml.

[3] LIU Z, ANDERSON T D, CRUZ J M. Consumer environmental awareness and competition in two-stage supply chains [J].European J of Operational Research, 2012, 218(3):602-613.

[4] Ji-lie Lu. "the 12th five-year plan" low-carbon concept, the real driving force is consumers[EB/OL].(2010-12-02). http://www.ce.cn/cysc/newmain/right/zg/201012/02/t20101 202_20560262.shtml.

[5] Jian-ni Liu. Research on dual-channel pricing strategy of supply chain in free-rider environment [D]. Northeast: 
Northeastern University,2014.

[6] CHIANG W K, CHHAJED D, HESS J D. Direct marketing, indirect profits: A strategic analysis of dual-channel supply-chain design [J]. Management Science, 2003, 49(1):1-20.

[7] DUMRONGSIRI A, FAN M, JAIN A, et al. A supply chain model with direct and retail channels $[\mathrm{J}]$. European $\mathrm{J}$ of Operational Research, 2008, 187(3) : 691-718.

[8] CHEN J, ZHANG H, SUN Y. Implementing coordination contracts in a manufacturer Stackelberg dual-channel supply chain [J]. Omega, 2012, 40(5) : 571-583.

[9] Shi-hui Yang, Dao-dong Xiao. Channel selection and coordination of two-stage low-carbon supply chain [J]. Soft science,2017,31(3):92-98.

[10] Wei-dong Huang, Dian-zhong Xue, Yong-hua Gong. Differential game model for collaborative technological innovation of low-carbon supply chain [J]. Journal of Nanjing university of posts and telecommunications,2015,35(4):15-20.

[11] Qing-peng Wang, Dao-zhi Zhao. Cooperative strategy of two-stage supply chain emission reduction and promotion [J]. Control and decision-making,2014,29(2):307-314.

[12] Dao-zhi Zhao , Chun-qiu Xu, Qin-peng Wang. Differential game of joint emission reduction and low-carbon publicity considering retailer competition $[\mathrm{J}]$. Control and decision,2014,(10) :1809-1815.

[13] JØRGENSEN S, ZACCOUR G. A differential game of retailer promotions [J]. Automatica, 2003, 39(7) : 1145-1155.

[14] JØRGENSEN S, TABOUBI S, ZACCOUR G. Cooperative advertising in a marketing channel $[\mathrm{J}]$. $\mathrm{J}$ of Optimization Theory and Applications, 2001, 110(1) : 145-158.

[15] JØRGENSEN S, SIGUE S P, ZACCOUR G. Dynamic cooperative advertising in a channel $[\mathrm{J}]$. $\mathrm{J}$ of Retailing, 2000, 76(1) : 71-92.

[16] JØRGENSEN S, ZACCOUR G. Equilibrium pricing and advertising strategies in a marketing channel $[\mathrm{J}]$. $\mathrm{J}$ of Optimization Theory and Applications, 1999, 102(1) : 111-125.

[17] JØRGENSEN S, ZACCOUR G. Channel coordination over time: Incentive equilibria and credibility $[\mathrm{J}] . \mathrm{J}$ of EconomicDynamics \& Control, 2003, 27(5) : 801-822.

[18] JØRGENSEN S, TABOUBI S, ZACCOUR G. Retail promotions with negative brand image effects: Is ISSN: 2456-7620 cooperation possible?[J].European $\mathrm{J}$ of Operational Research, 2003, 150(2): 395-405.

[19] QiangFu,Shun-qiu Zeng. Research on differential game model of vertical cooperative advertising [J]. Systems engineering theory and practice,2007,27(11): 26-33.

[20] HE X, KRISHNAMOORTHY A, Prasad A, et al. Retail competition and cooperative advertising $[\mathrm{J}]$. Operations Research Letters, 2011,39(1): 11-16.

[21] Zhi-yong Zhang ,Hua-juan Li, Yang lei,Yong-qiang Shi. Research on coordination strategy of dual-channel advertising cooperation based on differential game $[\mathrm{J}]$. Control and decision,2014,29(5):873-879.

[22] Da-ming You,Differential game analysis of ecological $r \& d$, cooperative promotion and pricing of low-carbon supply chain [J]. Control and decision, 2016,31(6):1047-1056.

[23] Chun-qiuXu, Dao-zhi Zhao, Bai-yun Yuan, Long-fei He. Differential game model of upstream and downstream joint emission reduction and low-carbon publicity [J]. Journal of management science,2016,19(2):53-65. 